

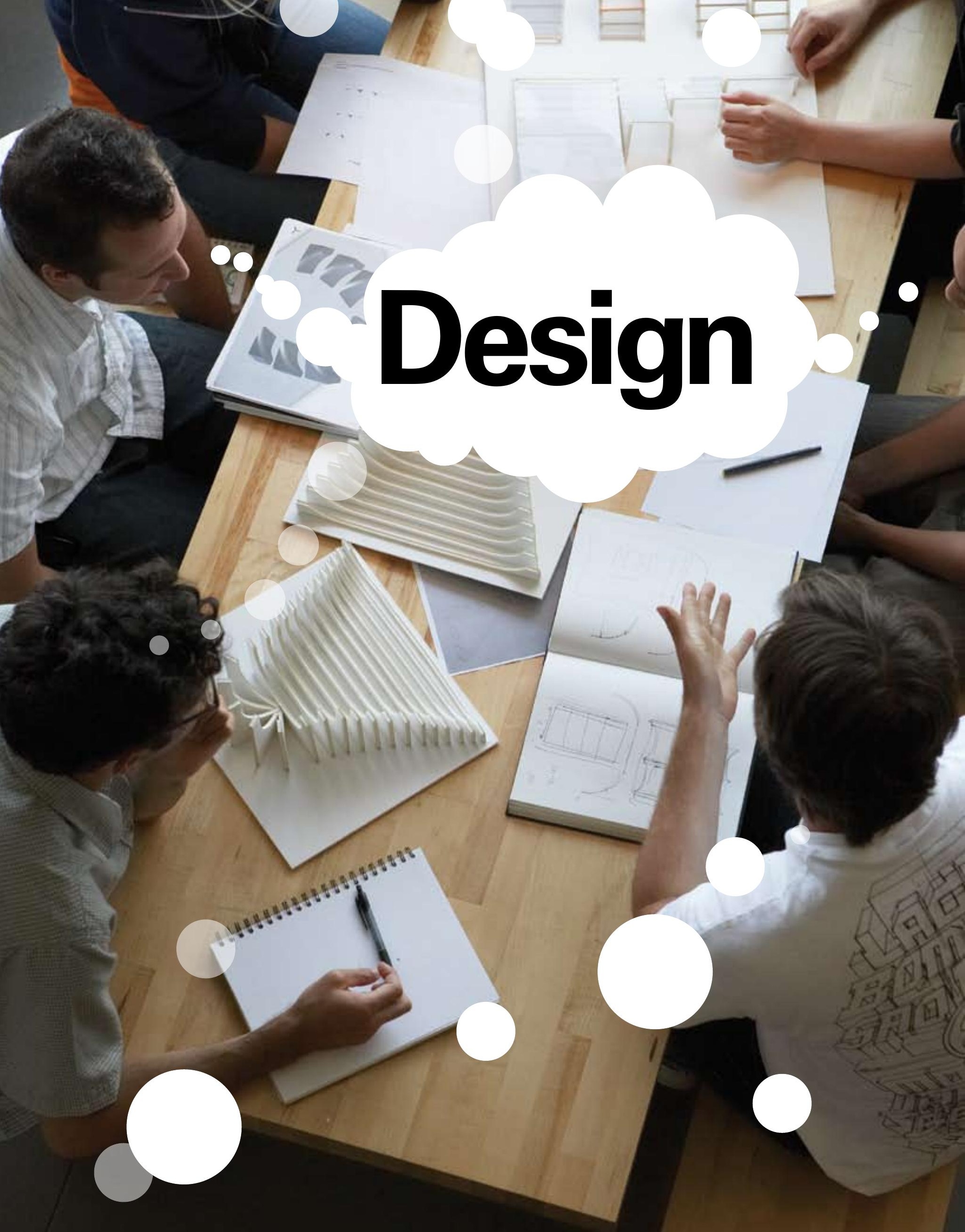



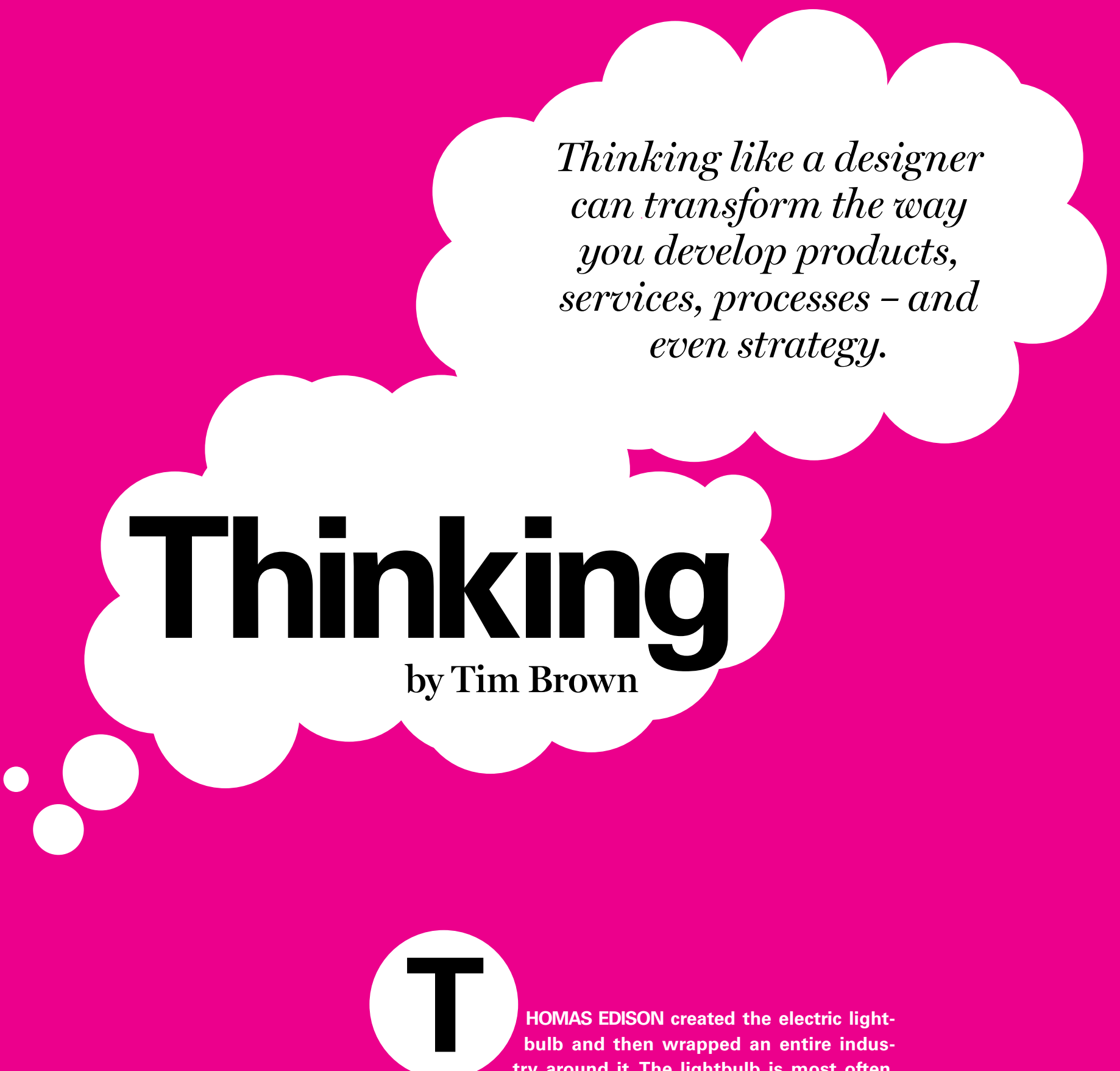

HOMAS EDISON created the electric lightbulb and then wrapped an entire industry around it. The lightbulb is most often thought of as his signature invention, but Edison understood that the bulb was little more than a parlor trick without a system of electric power generation and transmission to make it truly useful. So he created that, too.

Thus Edison's genius lay in his ability to conceive of a fully developed marketplace, not simply a discrete device. He was able to envision how people would want to use what he made, and he engineered toward that insight. He wasn't always prescient (he 
originally believed the phonograph would be used mainly as a business machine for recording and replaying dictation), but he invariably gave great consideration to users' needs and preferences.

Edison's approach was an early example of what is now called "design thinking"-a methodology that imbues the full spectrum of innovation activities with a human-centered design ethos. By this I mean that innovation is powered by a thorough understanding, through direct observation, of what people want and need in their lives and what they like or dislike about the way particular products are made, packaged, marketed, sold, and supported.

Many people believe that Edison's greatest invention was the modern R\&D laboratory and methods of experimental investigation. Edison wasn't a narrowly specialized scientist but a broad generalist with a shrewd business sense. In his Menlo Park, New Jersey, laboratory he surrounded himself with gifted tinkerers, improvisers, and experimenters. Indeed, he broke the mold of the "lone genius inventor" by creating a team-based approach to innovation. Although Edison biographers write of the camaraderie enjoyed by this merry band, the process also featured endless rounds of trial and error - the “99\% perspiration” in Edison's famous definition of genius. His approach was intended not to validate preconceived hypotheses but to help experimenters learn something new from each iterative stab. Innovation is hard work; Edison made it a profession that blended art, craft, science, business savvy, and an astute understanding of customers and markets.

Design thinking is a lineal descendant of that tradition. Put simply, it is a discipline that uses the designer's sensibility and methods to match people's needs with what is technologically feasible and what a viable business strategy can convert into customer value and market opportunity. Like Edison's painstaking innovation process, it often entails a great deal of perspiration.

I believe that design thinking has much to offer a business world in which most management ideas and best practices are freely available to be copied and exploited. Leaders now look to innovation as a principal source of differentiation and competitive advantage; they would do well to incorporate design thinking into all phases of the process.

\section{Getting Beneath the Surface}

Historically, design has been treated as a downstream step in the development process - the point where designers, who have played no earlier role in the substantive work of innovation, come along and put a beautiful wrapper around the idea. To be sure, this approach has stimulated market growth in many areas by making new products and technolo- gies aesthetically attractive and therefore more desirable to consumers or by enhancing brand perception through smart, evocative advertising and communication strategies. During the latter half of the twentieth century design became an increasingly valuable competitive asset in, for example, the consumer electronics, automotive, and consumer packaged goods industries. But in most others it remained a latestage add-on.

Now, however, rather than asking designers to make an already developed idea more attractive to consumers, companies are asking them to create ideas that better meet consumers' needs and desires. The former role is tactical, and results in limited value creation; the latter is strategic, and leads to dramatic new forms of value.

Moreover, as economies in the developed world shift from industrial manufacturing to knowledge work and service delivery, innovation's terrain is expanding. Its objectives are no longer just physical products; they are new sorts of processes, services, IT-powered interactions, entertainments, and ways of communicating and collaborating exactly the kinds of human-centered activities in which design thinking can make a decisive difference. (See the sidebar "A Design Thinker's Personality Profile.")

Consider the large health care provider Kaiser Permanente, which sought to improve the overall quality of both patients' and medical practitioners' experiences. Businesses in the service sector can often make significant innovations on the front lines of service creation and delivery. By teaching design thinking techniques to nurses, doctors, and administrators, Kaiser hoped to inspire its practitioners to contribute new ideas. Over the course of several months Kaiser teams participated in workshops with the help of my firm, IDEO, and a group of Kaiser coaches. These workshops led to a portfolio of innovations, many of which are being rolled out across the company.

One of them - a project to reengineer nursing-staff shift changes at four Kaiser hospitals - perfectly illustrates both the broader nature of innovation "products" and the value of a holistic design approach. The core project team included a strategist (formerly a nurse), an organizational-development specialist, a technology expert, a process designer, a union representative, and designers from IDEO. This group worked with innovation teams of frontline practitioners in each of the four hospitals.

During the earliest phase of the project, the core team collaborated with nurses to identify a number of problems in the way shift changes occurred. Chief among these was the fact that nurses routinely spent the first 45 minutes of each shift at the nurses' station debriefing the departing shift about the status of patients. Their methods of information exchange were 


\section{A Design Thinker's Personality Profile}

\author{
Contrary to popular opinion, you don't need \\ weird shoes or a black turtleneck to be a design \\ thinker. Nor are design thinkers necessarily cre- \\ ated only by design schools, even though most \\ professionals have had some kind of design train- \\ ing. My experience is that many people outside \\ professional design have a natural aptitude for \\ design thinking, which the right development \\ and experiences can unlock. Here, as a starting \\ point, are some of the characteristics to look for \\ in design thinkers:
}

Empathy. They can imagine the world from multiple perspectives - those of colleagues, clients, end users, and customers (current and prospective). By taking a "people first" approach, design thinkers can imagine solutions that are inherently desirable and meet explicit or latent needs. Great design thinkers observe the world in minute detail. They notice things that others do not and use their insights to inspire innovation.

Integrative thinking. They not only rely on analytical processes (those that produce either/or choices) but also exhibit the ability to see all of the salient - and sometimes contradictory - aspects of a confounding problem and create novel solutions that go beyond and dramatically improve on existing alternatives. (See Roger Martin's The Opposable Mind: How Successful Leaders Win Through Integrative Thinking.)

Optimism. They assume that no matter how challenging the constraints of a given problem, at least one potential solution is better than the existing alternatives.

Experimentalism. Significant innovations don't come from incremental tweaks. Design thinkers pose questions and explore constraints in creative ways that proceed in entirely new directions.

Collaboration. The increasing complexity of products, services, and experiences has replaced the myth of the lone creative genius with the reality of the enthusiastic interdisciplinary collaborator. The best design thinkers don't simply work alongside other disciplines; many of them have significant experience in more than one. At IDEO we employ people who are engineers and marketers, anthropologists and industrial designers, architects and psychologists. different in every hospital, ranging from recorded dictation to face-to-face conversations. And they compiled the information they needed to serve patients in a variety of ways - scrawling quick notes on the back of any available scrap of paper, for example, or even on their scrubs. Despite a significant investment of time, the nurses often failed to learn some of the things that mattered most to patients, such as how they had fared during the previous shift, which family members were with them, and whether or not certain tests or therapies had been administered. For many patients, the team learned, each shift change felt like a hole in their care. Using the insights gleaned from observing these important times of transition, the innovation teams explored potential solutions through brainstorming and rapid prototyping. (Prototypes of a service innovation will of course not be physical, but they must be tangible. Because pictures help us understand what is learned through prototyping, we often videotape the performance of prototyped services, as we did at Kaiser.)

Prototyping doesn't have to be complex and expensive. In another health care project, IDEO helped a group of surgeons develop a new device for sinus surgery. As the surgeons described the ideal physical characteristics of the instrument, one of the designers grabbed a whiteboard marker, a film canister, and a clothespin and taped them together. "Do you mean like this?" he asked. With his rudimentary prototype in hand, the surgeons were able to be much more precise about what the ultimate design should accomplish.

Prototypes should command only as much time, effort, and investment as are needed to generate useful feedback and evolve an idea. The more "finished" a prototype seems, the less likely its creators will be to pay attention to and profit from feedback. The goal of prototyping isn't to finish. It is to learn about the strengths and weaknesses of the idea and to identify new directions that further prototypes might take.

The design that emerged for shift changes had nurses passing on information in front of the patient rather than at the nurses' station. In only a week the team built a working prototype that included new procedures and some simple software with which nurses could call up previous shift-change notes and add new ones. They could input patient information throughout a shift rather than scrambling at the end to pass it on. The software collated the data in a simple format customized for each nurse at the start of a shift. The result was both higher-quality knowledge transfer and reduced prep time, permitting much earlier and better-informed contact with patients.

As Kaiser measured the impact of this change over time, it learned that the mean interval between a nurse's arrival and first interaction with a patient had been more than halved, adding a huge amount of nursing time across the four hospitals. Perhaps just as important was the effect on the quality of the nurses' work experience. One nurse commented, "I'm an hour ahead, and I've only been here 45 minutes." Another 
said, "[This is the] first time I've ever made it out of here at the end of my shift."

Thus did a group of nurses significantly improve their patients' experience while also improving their own job satisfaction and productivity. By applying a human-centered design methodology, they were able to create a relatively small process innovation that produced an outsize impact. The new shift changes are being rolled out across the Kaiser system, and the capacity to reliably record critical patient information is being integrated into an electronic medical records initiative at the company.

What might happen at Kaiser if every nurse, doctor, and administrator in every hospital felt empowered to tackle problems the way this group did? To find out, Kaiser has created the Garfield Innovation Center, which is run by Kaiser's original core team and acts as a consultancy to the entire organization. The center's mission is to pursue innovation that enhances the patient experience and, more broadly, to envision Kaiser's "hospital of the future." It is introducing tools for design thinking across the Kaiser system.

\section{How Design Thinking Happens}

The myth of creative genius is resilient: We believe that great ideas pop fully formed out of brilliant minds, in feats of imagination well beyond the abilities of mere mortals. But what the Kaiser nursing team accomplished was neither a sudden breakthrough nor the lightning strike of genius; it was the result of hard work augmented by a creative human-centered discovery process and followed by iterative cycles of prototyping, testing, and refinement.

The design process is best described metaphorically as a system of spaces rather than a predefined series of orderly steps. The spaces demarcate different sorts of related activities that together form the continuum of innovation. Design thinking can feel chaotic to those experiencing it for the first time. But over the life of a project participants come to see - as they did at Kaiser - that the process makes sense and achieves results, even though its architecture differs from the linear, milestone-based processes typical of other kinds of business activities.

Design projects must ultimately pass through three spaces (see the exhibit at right). We label these "inspiration," for the circumstances (be they a problem, an opportunity, or both) that motivate the search for solutions; "ideation," for the pro- 


\section{Inspiration}

\section{Expect Success}

Build implementation resources into your plan

What's the business problem? Where's the opportunity? What has changed (or soon may change)?

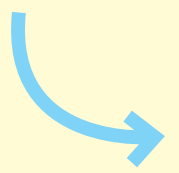

Involve many disciplines from the start (e.g., engineering \& marketing)

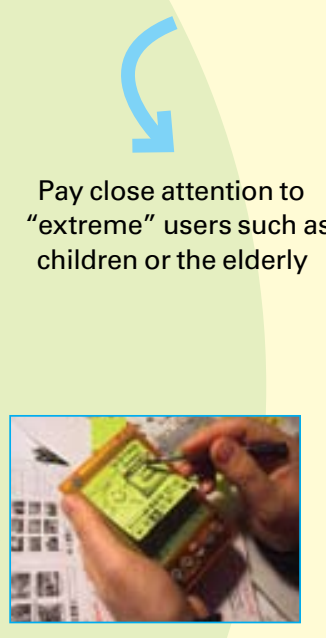

Are valuable ideas, assets, and expertise hiding inside the business?

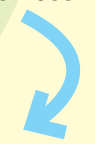

Organize information and synthesize possibilities (tell more stories!)

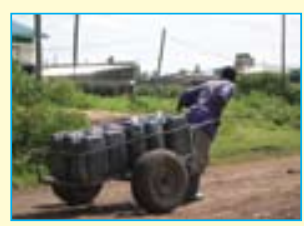

Look at the world: Observe what people do, how they think, what they need and want

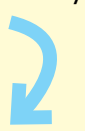

What are the business constraints (time, lack of resources, impoverished customer base, shrinking market)?

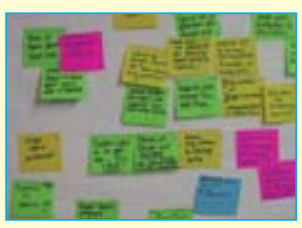

Have a project room where you can share insights, tell stories

How can new technology help? cess of generating, developing, and testing ideas that may lead to solutions; and "implementation," for the charting of a path to market. Projects will loop back through these spaces particularly the first two - more than once as ideas are refined and new directions taken.

Sometimes the trigger for a project is leadership's recognition of a serious change in business fortunes. In 2004 Shimano,

a Japanese manufacturer of bicycle components, faced flattening growth in its traditional high-end road-racing and mountain-bike segments in the United States. The company had always relied on technology innovations to drive its growth and naturally tried to predict where the next one might come from. This time Shimano thought a high-end casual bike that appealed to boomers would be an interesting area to explore. IDEO was invited to collaborate on the project.

During the inspiration phase, an interdisciplinary team of IDEO and Shimano people-designers, behavioral scientists, marketers, and engineers - worked to identify appropriate constraints for the project. The team began with a hunch that it should focus more broadly than on the high-end market, which might prove to be neither the only nor even the best source of new growth. So it set out to learn why 90\% of American adults don't ride bikes. Looking for new ways to think about the problem, the team members spent time with all kinds of consumers. They discovered that nearly everyone they met rode a bike as a child and had happy memories of doing so. They also discovered that many Americans are intimidated by cycling today - by the retail experience (including the young, Lycra-clad athletes who serve as sales staff in most independent bike stores); by the complexity and cost of the bikes, accessories, and specialized clothing; by the danger of cycling on roads not designed for bicycles; and by the demands of maintaining a technically sophisticated bike that is ridden infrequently.

This human-centered exploration - which took its insights from people outside Shimano's core customer base - led to the realization that a whole new category of bicycling might be able to reconnect American consumers to their experiences as children while also dealing with the root causes of their feelings of intimidation - thus revealing a large untapped market.

The design team, responsible for every aspect of what was envisioned as a holistic experience, came up with the concept of "Coasting." Coasting would aim to entice lapsed bikers into 


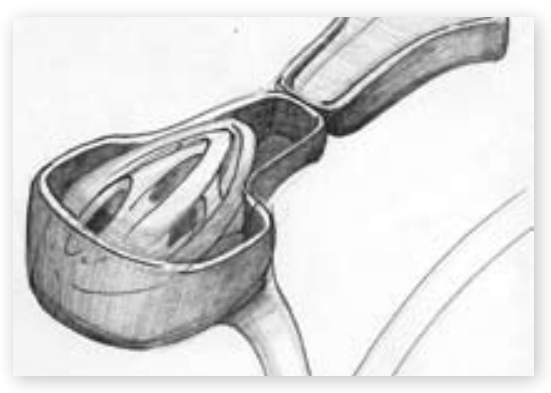

an activity that was simple, straightforward, and fun. Coasting bikes, built more for pleasure than for sport, would have no controls on the handlebars, no cables snaking along the frame. As on the earliest bikes many of us rode, the brakes would be applied by backpedaling. With the help of an onboard computer, a minimalist three gears would shift automatically as the bicycle gained speed or slowed. The bikes would feature comfortably padded seats, be easy to operate, and require relatively little maintenance.

Three major manufacturers - Trek, Raleigh, and Giant - developed new bikes incorporating innovative components from Shimano. But the design team didn't stop with the bike itself. In-store retailing strategies were created for independent bike dealers, in part to alleviate the discomfort that biking novices felt in stores designed to serve enthusiasts. The team developed a brand that identified Coasting as a way to enjoy life. ("Chill. Explore. Dawdle. Lollygag. First one there's a rotten egg.") And it designed a public relations campaign - in collaboration with local governments and cycling organizations - that identified safe places to ride.

Although many others became involved in the project when it reached the implementation phase, the application of design thinking in the earliest stages of innovation is what led to this complete solution. Indeed, the single thing one

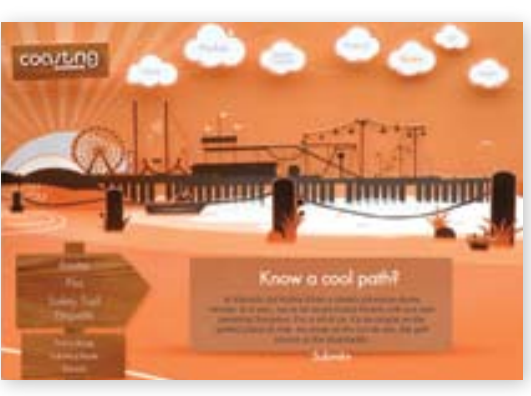

would have expected the design team to be responsible for - the look of the bikes - was intentionally deferred to later in the development process, when the team created a reference design to inspire the bike companies' own design teams. After a successful launch in 2007, seven more bicycle manufacturers signed up to produce Coasting bikes in 2008.

\section{Taking a Systems View}

Many of the world's most successful brands create breakthrough ideas that are inspired by a deep understanding of consumers' lives and use the principles of design to innovate and build value. Sometimes innovation has to account for vast differences in cultural and socioeconomic conditions. In such cases design thinking can suggest creative alternatives to the assumptions made in developed societies.

India's Aravind Eye Care System is probably the world's largest provider of eye care. From April 2006 to March 2007 Aravind served more than 2.3 million patients and performed more than 270,00o surgeries. Founded in 1976 by Dr. G. Venkataswamy, Aravind has as its mission nothing less than the eradication of needless blindness among India's population, including the rural poor, through the effective delivery of superior ophthalmic care. (One of the company's slogans is "Quality is for everyone.”) From 11 beds in Dr. Venkataswamy's home, Ara-

\section{How to Make Design Thinking Part of the Innovation Drill}

Begin at the beginning.

Involve design thinkers at the very start of the innovation process, before any direction has been set. Design thinking will help you explore more ideas more quickly than you could otherwise.

\author{
Take a human-centered \\ approach. Along with busi- \\ ness and technology consider- \\ ations, innovation should factor \\ in human behavior, needs, and \\ preferences. Human-centered \\ design thinking - especially \\ when it includes research \\ based on direct observation - \\ will capture unexpected in- \\ sights and produce innovation \\ that more precisely reflects \\ what consumers want.
}

\author{
Try early and often. \\ Create an expectation of rapid \\ experimentation and prototyp- \\ ing. Encourage teams to create \\ a prototype in the first week \\ of a project. Measure progress \\ with a metric such as aver- \\ age time to first prototype or \\ number of consumers exposed \\ to prototypes during the life of \\ a program.
} Seek outside help.
Expand the innovation
ecosystem by looking for
opportunities to co-create
with customers and consum-
ers. Exploit Web 2.0 networks
to enlarge the effective scale
of your innovation team. 


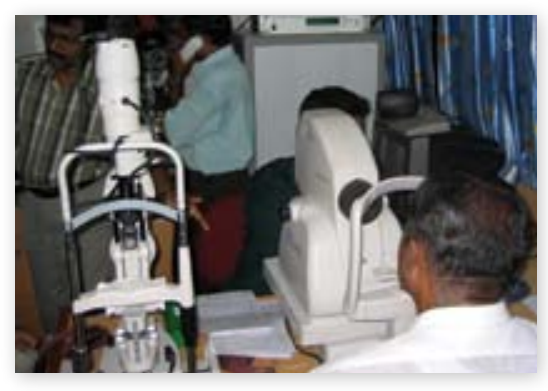

vind has grown to encompass five hospitals (three others are under Aravind management), a plant that manufactures ophthalmic products, a research foundation, and a training center.

Aravind's execution of its mission and model is in some respects reminiscent of Edison's holistic concept of electric power delivery. The challenge the company faces is logistic: how best to deliver eye care to populations far removed from the urban centers where Aravind's hospitals are located. Aravind calls itself an "eye care system" for a reason: Its business goes beyond ophthalmic care per se to transmit expert practice to populations that have historically lacked access. The company saw its network of hospitals as a beginning rather than an end.

Much of its innovative energy has focused on bringing both preventive care and diagnostic screening to the countryside. Since 1990 Aravind has held "eye camps" in India's rural areas, in an effort to register patients, administer eye exams, teach eye care, and identify people who may require surgery or advanced diagnostic services or who have conditions that warrant monitoring.

In 2006 and early 2007 Aravind eye camps screened more than 500,000 patients, of whom nearly 113,000 required surgery. Access to transportation is a common problem in rural areas, so the company provides buses that take patients needing further

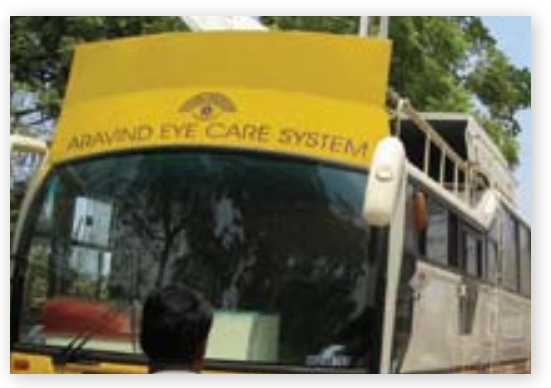

treatment to one of its urban facilities and then home again. Over the years it has bolstered its diagnostic capabilities in the field with telemedicine trucks, which enable doctors back at Aravind's hospitals to participate in care decisions. In recent years Aravind's analysis of its screening data has led to specialized eye camps for certain demographic groups, such as school-age children and industrial and government workers; the company also holds camps specifically to screen for eye diseases associated with diabetes. All these services are free for the roughly $60 \%$ of patients who cannot afford to pay.

In developing its system of care, Aravind has consistently exhibited many characteristics of design thinking. It has used as a creative springboard two constraints: the poverty and remoteness of its clientele and its own lack of access to expensive solutions. For example, a pair of intraocular lenses made in the West costs $\$ 200$, which severely limited the number of patients Aravind could help. Rather than try to persuade suppliers to change the way they did things, Aravind built its own solution: a manufacturing plant in the basement of one of its hospitals. It eventually discovered that it could use relatively inexpensive technology to produce lenses for $\$ 4$ a pair.

Throughout its history - defined by the constraints of poverty, ignorance, and an enormous unmet need - Aravind has built a systemic solution to a complex social and medical problem.

Blend big and small

projects. Manage a portfolio

of innovation that stretches

from shorter-term incremental

ideas to longer-term revolu-

tionary ones. Expect busi-

ness units to drive and fund

incremental innovation, but be

willing to initiate revolutionary

innovation from the top.

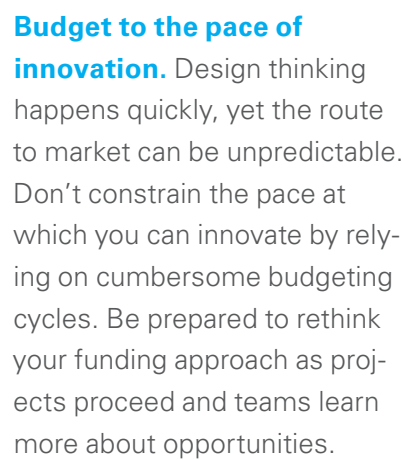

Find talent any way you can.

Look to hire from interdisci-

plinary programs like the new

Institute of Design at Stanford

and progressive business

schools like Rotman, in Toronto.

People with more-conventional

design backgrounds can push

solutions far beyond your

expectations. You may even be

able to train nondesigners with

the right attributes to excel in

design-thinking roles.
Design for the cycle.

In many businesses people

move every 12 to 18 months.

But design projects may take

longer than that to get from

day one through implementa-

tion. Plan assignments so

that design thinkers go from

inspiration to ideation to imple-

mentation. Experiencing the full

cycle builds better judgment

and creates great long-term

benefits for the organization. 


\section{Getting Back to the Surface}

I argued earlier that design thinking can lead to innovation that goes beyond aesthetics, but that doesn't mean that form and aesthetics are unimportant. Magazines like to publish photographs of the newest, coolest products for a reason: They are sexy and appeal to our emotions. Great design satisfies both our needs and our desires. Often the emotional connection to a product or an image is what engages us in the first place. Time and again we see successful products that were not necessarily the first to market but were the first to appeal to us emotionally and functionally. In other words, they do the job and we love them. The iPod was not the first MP3 player, but it was the first to be delightful. Target's products appeal emotionally through design and functionally through price - simultaneously.

This idea will grow ever more important in the future. As Daniel Pink writes in his book A Whole New Mind, "Abundance has satisfied, and even over-satisfied, the material needs of millions - boosting the significance of beauty and emotion and accelerating individuals' search for meaning." As more of our basic needs are met, we increasingly expect sophisticated experiences that are emotionally satisfying and meaningful. These experiences will not be simple products. They will be complex combinations of products, services, spaces, and information. They will be the ways we get educated, the ways we are entertained, the ways we stay healthy, the ways we share and communicate. Design thinking is a tool for imagining these experiences as well as giving them a desirable form.

One example of experiential innovation comes from a financial services company. In late 2005 Bank of America launched a new savings account service called "Keep the Change." IDEO, working with a team from the bank, helped identify a consumer behavior that many people will recognize: After paying cash for something, we put the coins we received in change into a jar at home. Once the jar is full, we take the coins to the bank and deposit them in a savings account. For many people, it's an easy way of saving. Bank of America's innovation was to build this behavior into a debit card account. Customers who use their debit cards to make purchases can now choose to have the total rounded up to the nearest dollar and the difference deposited in their savings accounts.

The success of this innovation lay in its appeal to an instinctive desire we have to put money aside in a painless and invisible way. Keep the Change creates an experience that feels natural because it models behavior that many of us already exhibit. To be sure, Bank of America sweetens the deal by matching $100 \%$ of the change saved in the first three months and $5 \%$ of annual totals (up to $\$ 250$ ) thereafter. This encourages customers to try it out. But the real payoff is emotional: the gratification that comes with monthly statements showing customers they've saved money without even trying.

In less than a year the program attracted 2.5 million customers. It is credited with 700,000 new checking accounts and a million new savings accounts. Enrollment now totals more than 5 million people who together have saved more than $\$ 500$ million. Keep the Change demonstrates that design thinking can identify an aspect of human behavior and then convert it into both a customer benefit and a business value.

Thomas Edison represents what many of us think of as a golden age of American innovation - a time when new ideas transformed every aspect of our lives. The need for transformation is, if anything, greater now than ever before. No matter where we look, we see problems that can be solved only through innovation: unaffordable or unavailable health care, billions of people trying to live on just a few dollars a day, energy usage that outpaces the planet's ability to support it, education systems that fail many students, companies whose traditional markets are disrupted by new technologies or demographic shifts. These problems all have people at their heart. They require a human-centered, creative, iterative, and practical approach to finding the best ideas and ultimate solutions. Design thinking is just such an approach to innovation.

Tim Brown (tbrown@ideo.com) is the CEO and president of IDEO, an innovation and design firm with headquarters in Palo Alto, California. His designs have won numerous awards and been exhibited at the Museum of Modern Art in New York, the Axis Gallery in Tokyo, and the Design Museum in London.

\section{Reprint R0806E}

